\title{
The association between blood pressure and serum cholesterol in healthy men: the Oslo study
}

\author{
I. HJERMANN, A. HELGELAND, I. HOLME, \\ P. G. LUND-LARSEN, AND P. LEREN
}

From the Medical Outpatient Clinic and Life Insurance Companies' Institute for Medical Statistics, Ullevaal Hospital, Oslo, Norway

SUMMARY The association between serum cholesterol and blood pressure (BP) has been studied in 16525 men. The study reveals that these Oslo men in their forties present with a serum cholesterol value which is on average $0.71 \mathrm{mmol} / 1(27.4 \mathrm{mg} / 100 \mathrm{ml})$ higher at diastolic BP $>110 \mathrm{mmHg}$ than at BP $<70 \mathrm{mmHg}$. According to earlier studies in Oslo, this cholesterol difference alone imparts a 10 -year myocardial infarction morbidity difference of $25-30 \%$. These findings might be of practical importance for epidemiological studies and for preventive measures against the two factors. The influence of other variables on the association between blood pressure and cholesterol has been studied in a multivariate analysis. Of these variables, only body mass index and serum triglycerides significantly influence the relationship between blood pressure and cholesterol, whereas age, cigarette smoking, non-fasting blood sugar, season, socioeconomic status, and physical activity at work and leisure do not influence the correlation.

\section{Introduction}

Studies of the association between serum cholesterol and blood pressure have resulted in different conclusions (Carlsson and Lindstedt, 1968; Natvig et al., 1968; Hagerup, 1973; Wilhelmsen et al., 1973; Pincherle and Robinson, 1974; Stamler et al., 1975; Bulpitt et al., 1976; Ostrander, 1976). This may be due to differences in the design of these studies and to differences in age, sex, risk factor levels, and geographical areas. In previous papers, the associations between serum cholesterol and cigarette smoking (Hjermann et al., 1976) and risk variables and socioeconomic status (Holme et al., 1976) have been reported. In the present study the relationship between serum cholesterol and blood pressure is discussed.

\section{Material and methods}

In the Oslo study all men aged 40 to 49 , and a $7 \%$ random sample of men aged 20 to 39, were asked to attend a screening examination of coronary risk factors in 1972-73. Approximately 18000 men were examined, of whom 16525 , aged 20 to 49, were defined as 'healthy'; that is, free of symptoms and signs of cardiovascular disease and diabetes. The variables recorded were: body weight and height, blood pressure, non-fasting serum cholesterol, triglycerides and glucose, degree of physical activity at work and at leisure, smoking habits, and subjective feeling of mental stress. The screening procedure, attendance rate, laboratory methods, and main results have previously been reported (Leren et al., 1976). Blood pressure was measured according to methods recommended by the World Health Organisation (Rose and Blackburn, 1968).

\section{Statistics}

Differences between means have been tested by a modified Student's $t$ test, using crude non-adjusted means. In a more detailed statistical analysis of the association between blood pressure and cholesterol in more than 14000 men aged 40 to 49 , a multivariate analysis was performed, calculating correlation coefficients adjusted for eight variables.

Initially a multiple linear regression model without interaction effects was constructed to analyse the relationship between serum cholesterol and the following nine risk factors: systolic blood pressure (S.BP), diastolic blood pressure (D.BP), serum triglycerides (TRI), serum glucose (Gluc), age, daily number of cigarettes (Cig), body mass index $\left(\mathrm{W} / \mathrm{H}^{2}\right)$, 
seasonal variation (S.V.), socioeconomic status (SES), physical activity (P.A.) at work and at leisure combined. The relations can be written:

(a) $\mathrm{Chol}=\mathrm{a}_{1}+\mathrm{a}_{2} \mathrm{TRI}+\mathrm{a}_{3} \mathrm{~S} . \mathrm{BP}+\mathrm{a}_{4} \mathrm{Gluc}+\mathrm{a}_{5} \mathrm{Age}+\mathrm{a}_{6} \mathrm{Cig}+\mathrm{a}_{7} \mathrm{~W} / \mathrm{H}^{2}+$ $a_{8}$ SES $+a_{9}$ S.V. $+a_{10} P . A$.

(b) $\mathrm{Chol}=\mathrm{b}_{1}+\mathrm{b}_{2} \mathrm{TRI}+\mathrm{b}_{3} \mathrm{D}$.BP $+\mathrm{b}_{4}$ Gluc $+\mathrm{b}_{5} \mathrm{Age}+\mathrm{b}_{6} \mathrm{Cig}+\mathrm{b}_{7} \mathrm{~W} / \mathrm{H}^{2}+$ $b_{8} S E S+b_{9} S . V .+b_{10} P$.A.

The (a)s and (b)s are the regression coefficients representing the impact of each factor on cholesterol. Partial correlation coefficients were computed by the method of Ralston and Wilks (1960).

To obtain adjusted curves for the relationship between serum cholesterol and blood pressure, the following method was used: a linear regression model was constructed without interaction effects between serum cholesterol and all risk factors mentioned above, except blood pressure. Thus it was possible to estimate serum cholesterol by means of all risk factors other than blood pressure.

Within each decile of the blood pressure distributions, the estimation equation of serum cholesterol was used to determine the level of serum cholesterol, taking into account the mean level of all risk factors other than blood pressure.

When this estimated mean cholesterol is $c_{w}$, the total mean cholesterol $\mathrm{c}$, and the crude mean cholesterol within each decile $c_{b}$, the adjusted mean serum cholesterol $\left(c_{a d j}\right)$ is:

$$
c_{a d j}=\frac{c_{b} \cdot c}{c_{w}^{\prime}}
$$

\section{Results}

Figures 1 and 2 show a close correlation between blood pressure and cholesterol $(\mathrm{P}<0.01)$ in three different age groups. Table 1 lists the simple correlation coefficients, which are highly significant.

Blood pressure-specific age trend curves for serum cholesterol are shown in Figures 3 and 4.

Table 1 Simple correlation coefficients $(r)$ and their $t$-values for significance between cholesterol and blood pressure in healthy men aged 40 to 44 and 45 to 49.

\begin{tabular}{llll}
\hline Age group & & Chol/systolic BP & Chol/diastolic BP \\
\hline $40-44$ & n & 6910 & 6910 \\
& r & $0 \cdot 16$ & $0 \cdot 16$ \\
$45-49$ & t & $13 \cdot 5$ & $13 \cdot 5$ \\
& n & 7906 & 7906 \\
& r & $0 \cdot 12$ & $0 \cdot 11$ \\
& t & $10 \cdot 7$ & $9 \cdot 8$ \\
\hline
\end{tabular}

Again, it is demonstrated that the level of cholesterol is generally higher for the high blood pressure groups than for the lower. This finding is most pronounced for the diastolic blood pressure groups.

Analysis of partial correlation coefficients for the relationship between serum cholesterol and blood pressure at the ages of 40 to 49 is shown in Table 2. Relative body weight (body mass index) and non-fasting serum triglycerides strongly modify the positive correlation between blood pressure and cholesterol $(P<0 \cdot 01)$. When simultaneously adjusted for these variables, an additional but insignificant reduction in the correlation coefficient takes place. The addition of six other variables in the analysis (age, cigarette smoking, casual blood sugar, seasonal variation, five classes of socioeconomic status, and an index for physical activity at work or at leisure) makes no significant change in the cholesterol/blood pressure correlation coefficient.

The regression equations for cholesterol versus systolic and diastolic blood pressure were estimated as follows:

(a) $\mathrm{Chol}=121 \cdot 76+12 \cdot 32 \mathrm{TRI}+0 \cdot 234 \mathrm{~S} . \mathrm{BP}-0.047$ Gluc $+1 \cdot 175 \mathrm{Age}$ $+0.314 \mathrm{Cig}+0.546 \mathrm{~W} / \mathrm{H}^{2}+1.817 \mathrm{SES}+9.453 \mathrm{~S} . \mathrm{V}+$ 0.164 P.A.

(b) $\mathrm{Chol}=123 \cdot 16+12.35 \mathrm{TRI}+0.329 \mathrm{D} . \mathrm{BP}-0.025 \mathrm{Gluc}+1 \cdot 186 \mathrm{Age}$ $+0.319 \mathrm{Cig}+0.481 \mathrm{~W} / \mathrm{H}^{2}+1.817 \mathrm{SES}+9.453 \mathrm{~S} . \mathrm{V} .+$ $+0 \cdot 319$ Cig
0.164 P.A.

The significant explaining variables for cholestero色 are systolic/diastolic blood pressure, triglycerides age, body mass index, and seasonal variation However, the explaining power is rather weak, resulting in a multiple correlation coefficient of 0.42 , owing to the wide biological variation of the explaining variables.

Within each decile of systolic and diastolic blood pressure distribution, non-adjusted and adjusted cholesterol means are presented in Figures 5 and 6. It is shown that the blood pressure/cholesterol relationship is strongly modified by these eight variables $(\mathrm{P}<0 \cdot 01)$. However, a significant positive correlation still remains after adjustment for the eight variables, expressed also by the adjusted correlation coefficients in Table 2.

\section{Discussion}

The study presents a significant and almost linear correlation between blood pressure and serum

Table 2 Simple and partial correlation coefficients between blood pressure and cholesterol at ages 40 to 49 (n=14815)

\begin{tabular}{|c|c|c|c|c|c|}
\hline & \multirow[b]{2}{*}{$\begin{array}{l}\text { Simple } \\
\text { correlation } \\
\text { coefficients }\end{array}$} & \multicolumn{4}{|c|}{ Partial correlation coefficients, adjusted } \\
\hline & & $\begin{array}{l}\text { Body mass } \\
\text { index (BMI) }\end{array}$ & $\begin{array}{l}\text { Triglycerides } \\
(T R I)\end{array}$ & $B M I+T R I$ & $\begin{array}{l}B M I+T R I \\
+6 \text { other } \\
\text { variables } \neq\end{array}$ \\
\hline $\begin{array}{l}\text { Cholesterol/systolic BP } \\
\text { Cholesterol/diastolic BP }\end{array}$ & $\begin{array}{l}0 \cdot 14 \\
0 \cdot 14\end{array}$ & $\begin{array}{l}0.101 * \\
0.089 *\end{array}$ & $\begin{array}{l}0 \cdot 100^{*} \\
0.096^{*}\end{array}$ & $\begin{array}{l}0.089^{*} \\
0.080^{*}\end{array}$ & $\begin{array}{l}0.077^{*} \\
0.074^{*}\end{array}$ \\
\hline
\end{tabular}

* Significant change from simple to adjusted correlation coefficient $(P<0.01)$.

¥Age, daily number of cigarettes, serum glucose, seasonal variations, socioeconomic status, physical activity at work and at leisure. 


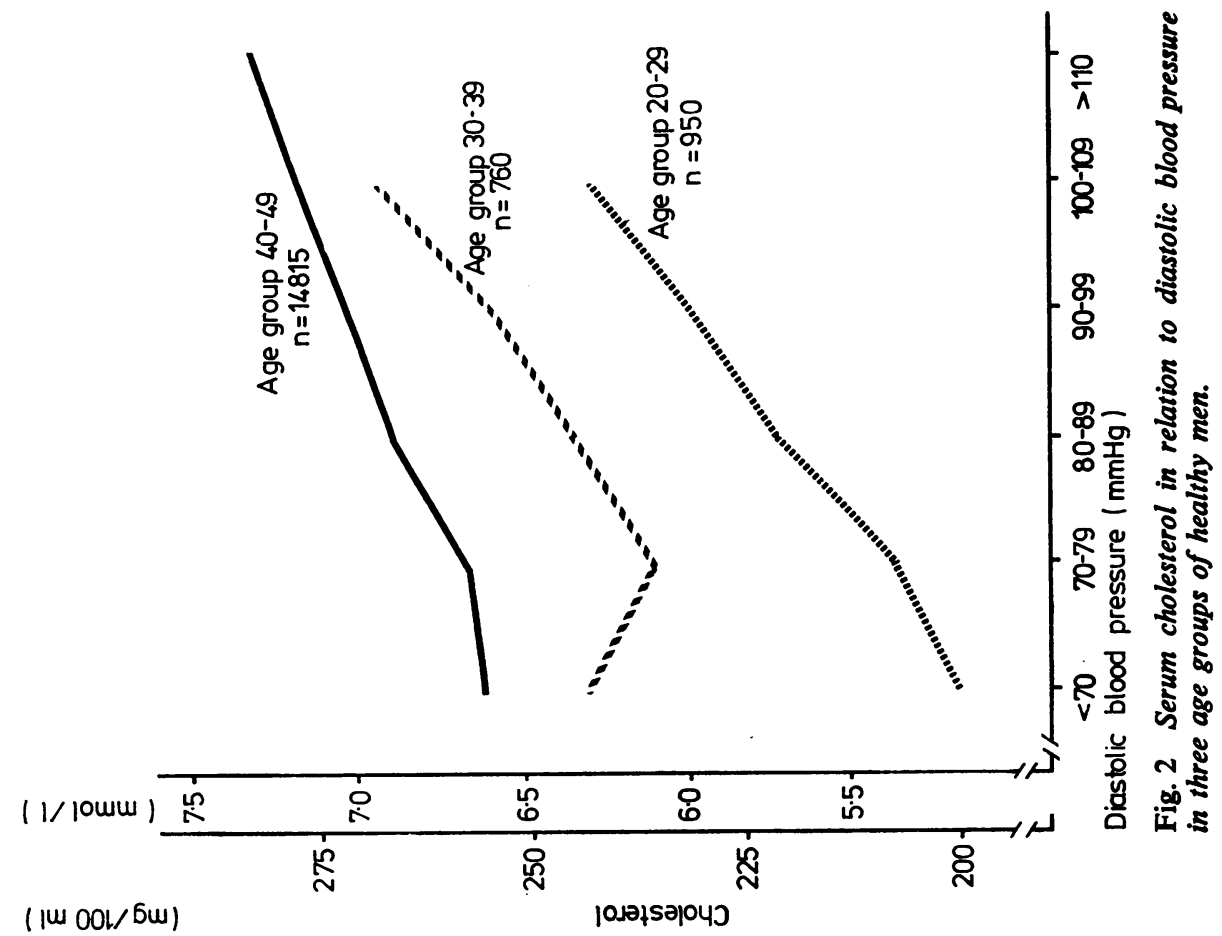

$(1 \mathrm{w} 00 \mathrm{k} / \mathrm{bw})$

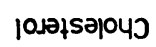

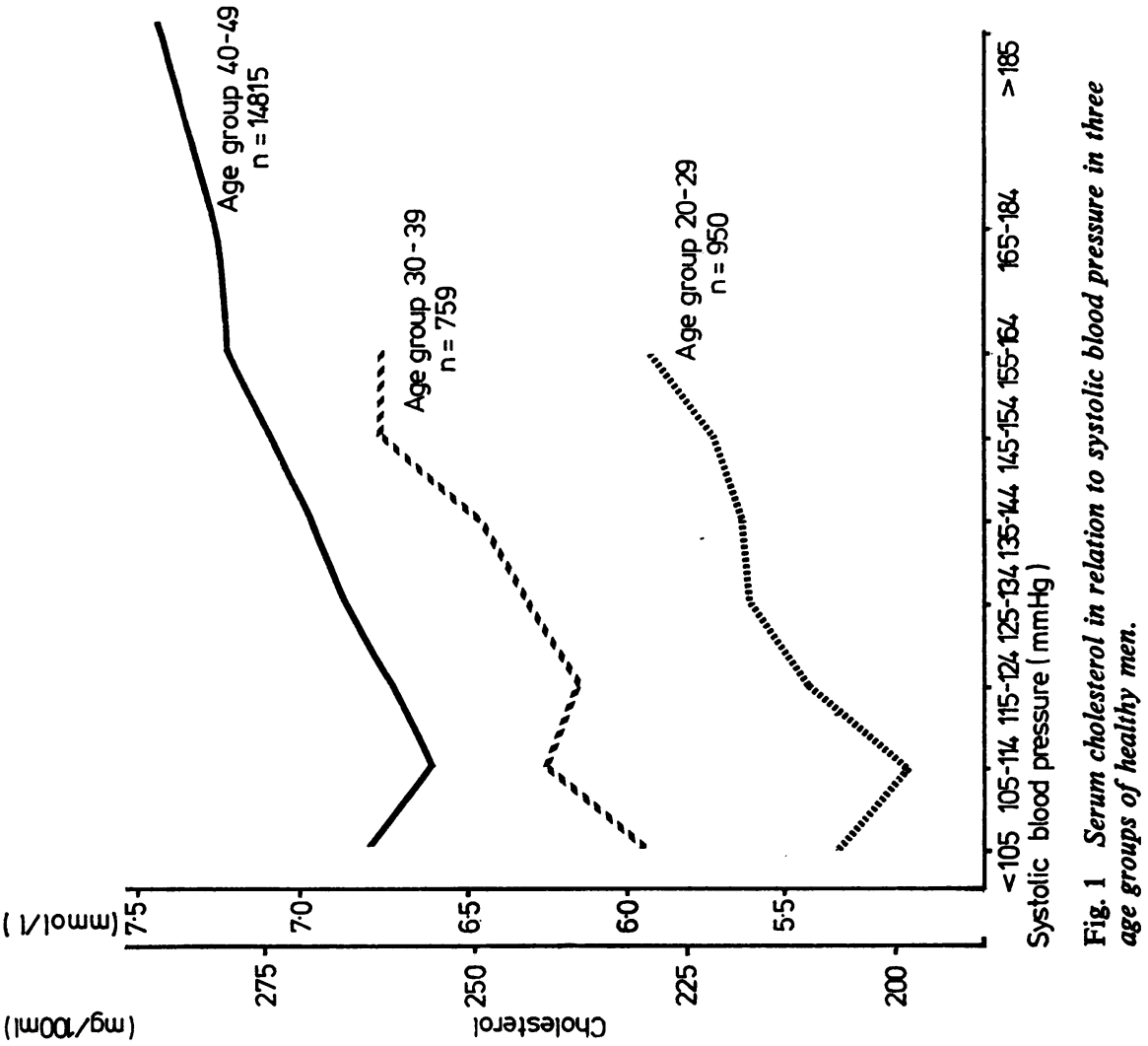




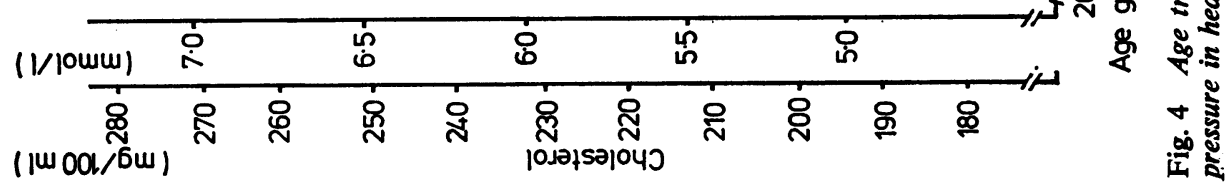

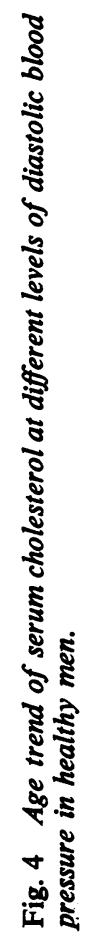

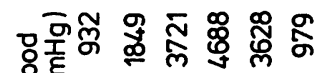

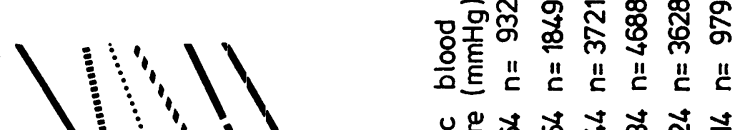

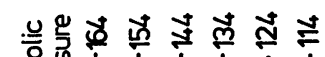

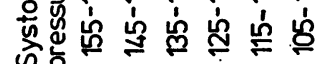

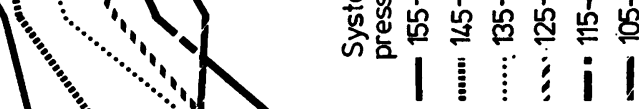

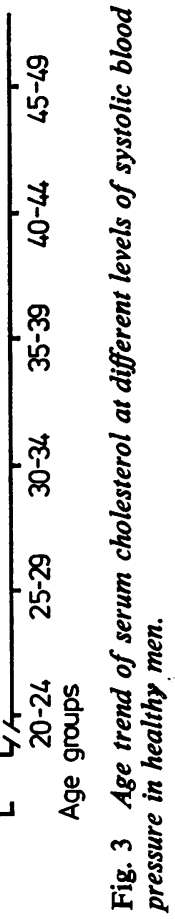


cholesterol. Thus, those with the highest blood pressure have a cholesterol level corresponding to that of low pressure men 10 to 15 years older. At the ages of 40 to 49 the cholestreol difference between diastolic pressure $<70 \mathrm{mmHg}$ and $>110$ (mean: 116) is $0.71 \mathrm{mmol} / 1(27.4 \mathrm{mg} / 100 \mathrm{ml})$. Such a difference in the cholesterol level imparts a 10-year difference in myocardial infarction incidence of $25-30 \%$, according to a previous study in Oslo (Westlund and Nicolaysen, 1972). Further, the combination of raised cholesterol and blood pressure has proved to be a powerful predictor of cardiovascular disease, carrying an almost multiplicative effect on coronary risk.

The lack of correlation between blood pressure and cholesterol past the age of 50 reported in the Tecumseh study (Ostrander, 1976) and in the Norwegian oil experiment, covering men aged 55 to 60 (Natvig et al., 1968), may be due to age factors. In the Danish study of men and women (Hagerup, 1973), no significant relationship was found between blood pressure and cholesterol at the age of 50. In that study, however, mean pressure was used in the analysis.

Two Swedish studies (Carlsson and Lindstedt, 1968; Wilhelmsen et al., 1973) have reported a weak blood pressure/cholesterol correlation. In studies of larger groups, that is, of about 36000 men and women in the USA including four population groups aged 25 to 64, Stamler et al. (1975) applied four different types of multivariate analysis. They concluded that 'the findings with respect to the relationship of serum cholesterol to blood pressure were generally negative, except for white males, where a high proportion of the multivariate analyses indicated a statistically significant relationship'.

In a study of about 12000 men in London (Pincherle and Robinson, 1974), a significant relationship was found between serum cholesterol and both systolic and diastolic blood pressure at all ages under 65 . The authors suggest, however, that this relationship could merely be a reflection of the joint correlation of these two variables with relative body weight. In the present study this hypothesis seems to be confirmed to some extent. As shown in Figures 5 and 6, not only relative body weight, but triglycerides, too, strongly modify the positive intercorrelation between blood pressure and cholesterol. This finding accords with the observation that both triglycerides and relative body weight are interrelated with cholesterol and blood pressure. The other six variables included in

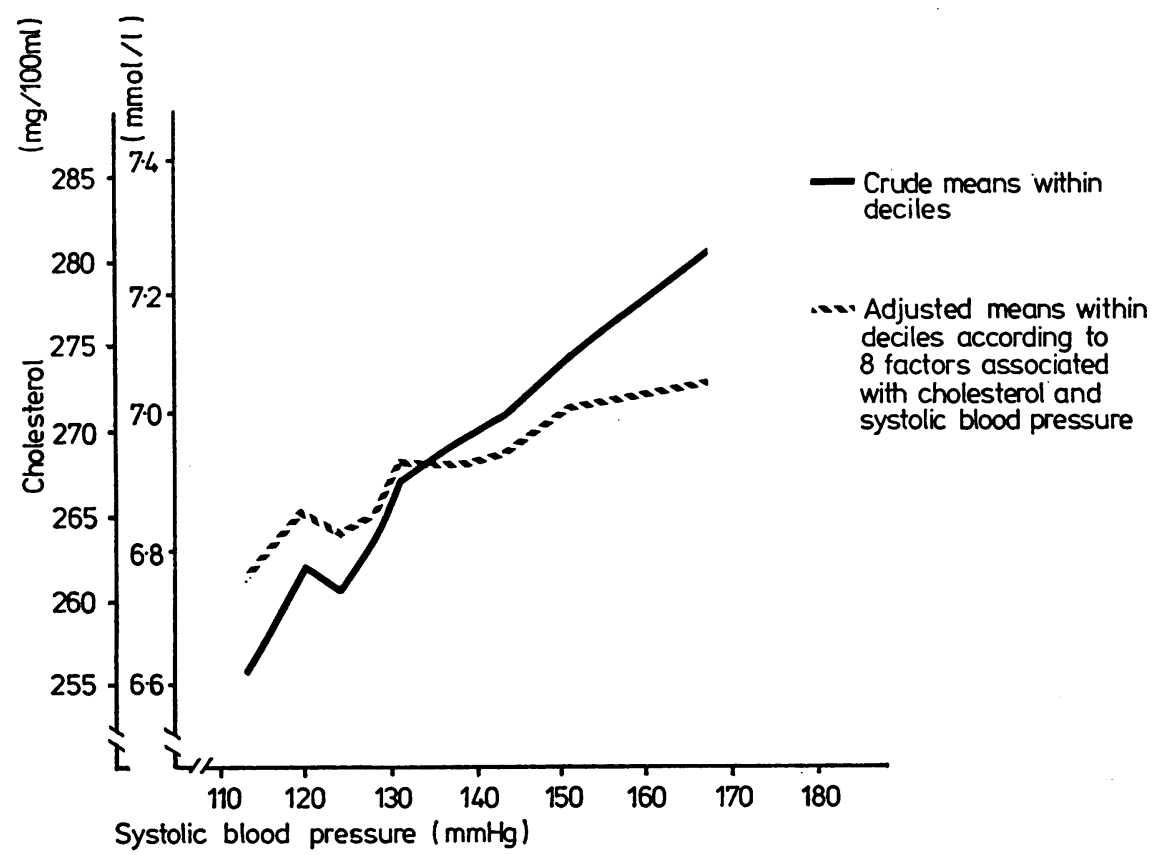

Fig. 5 Non-adjusted and adjusted correlation between systolic blood pressure and serum cholesterol (adjusted for weight/height ${ }^{2}$, serum triglycerides, glucose, age, cigarette smoking, seasonal variation, socioeconomic status and physical activity at work or at leisure); ages 40-49. 


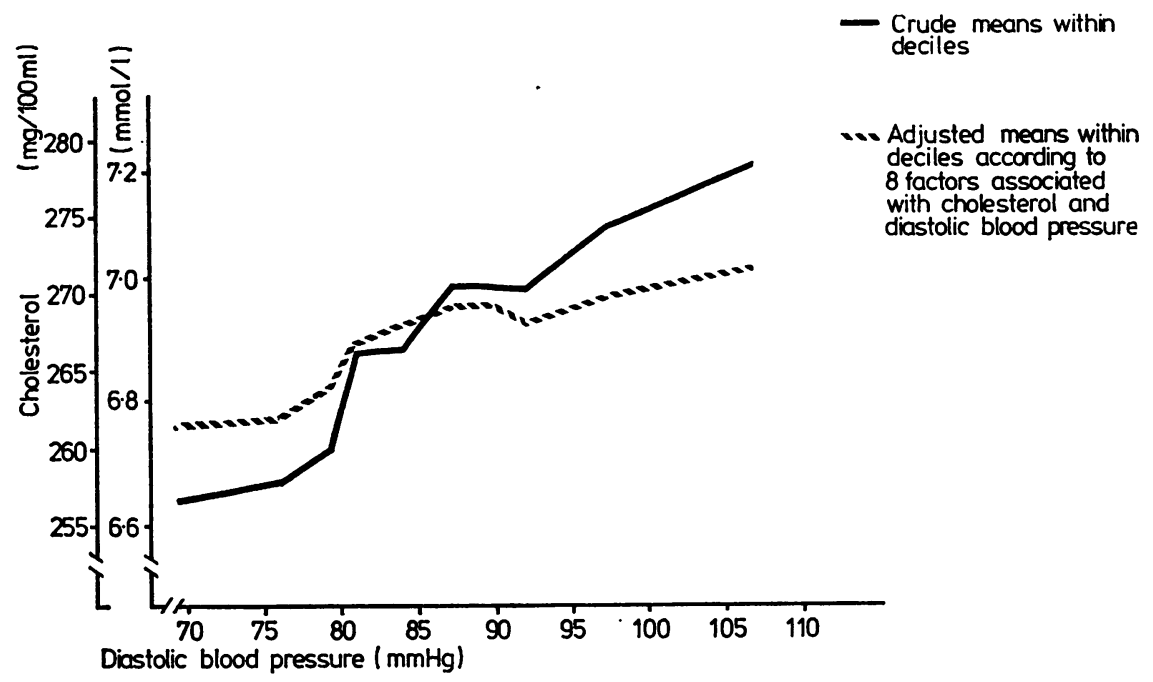

Fig. 6 Non-adjusted and adjusted correlation between diastolic blood pressure and serum cholesterol (adjusted for weight/height ${ }^{2}$, serum triglycerides, glucose, age, cigarette smoking, seasonal variation, socioeconomic status and physical activity at work or at leisure); ages 40-49.

the analysis, however, do not significantly modify the correlation further. The correlation coefficient, after adjustment for all eight variables at the same time, is still significantly different from zero, as indicated in Table 2 and Figures 5 and 6.

In the study of Bulpitt et al. (1976) only systolic and not diastolic pressure was found to be correlated to serum cholesterol. This observation is explained by the authors as the possible effect of reduction of great artery compliance during 'ageing' or atheroma formation, with an accompanying increase in systolic but not in diastolic pressure. In the present study, both systolic and diastolic pressure is correlated with serum cholesterol. This correlation does not increase with age as one might expect if the process of 'ageing' was involved.

Similar analyses were carried out in the United States National Health Survey (Florey and Acheson, 1969; Acheson and Baird, 1973). In those data the simple correlation between cholesterol and blood pressure was found to be a little higher than in our study, but as in the Oslo study, the correlation was reduced when the relationship with physique was taken into account.

We have shown a correlation between blood pressure and cholesterol which, though unquestionably real, is small. The trends shown in the graphs are stable because of the large numbers of men we have been abie to study in each age group.

The possibility that a selection at the screening examination could be responsible for the positive blood pressure/cholesterol correlation can be $\stackrel{ }{2}$ rejected, because the same correlation exists independently of degree of screening attendance (data not presented but available on request).

Whatever the explanation might be for the $\overrightarrow{0}$ cholesterol/blood pressure correlation, the presen $\infty$ study shows that these two important risk factors are in fact intercorrelated, and the relationship is explained only partly by variability in other risk variables, that is, relative body weight and triglycerides.

Our findings have the practical, clinical application that when one of the two factors, high blood pressure or high serum cholesterol, is present, the chance of the presence of the other one is increased. Also, in epidemiological studies this correlation should be taken into account when predicting coronary heart disease.

This study was supported by the City of Oslo, the Norwegian Council on Cardiovascular Diseases, and the Norwegian Drug Monopoly.

Reprints from I. Hjermann, Medical Outpatient Clinic, Ullevaal Hospital, Oslo 1, Norway.

\section{References}

Acheson, R.M., and Baird, J. T. (1973). Serum N cholesterol in a national sample of US adults: a study from prevalence data of its relationship to physique, blood pressure, blood glucose and other variables. International Journal of Epidemiology, 2, 283-292. 
Bulpitt, C. J., Hodes, C., and Everitt, M. G. (1976). The relationship between blood pressure and biochemical risk factors in a general population. British Journal of Preventive and Social Medicine, 30, 158-162.

Carlsson, L. A., and Lindstedt, S. (1968). The Stockholm Prospective Study I. Acta medica Scandinavica, Supplement 493, 126-127.

Florey, C. du V., and Acheson, R. M. (1969). Blood pressure as it relates to physique, blood glucose and serum cholesterol. Monographs of US National Center for Health Statistics, Series 11, No. 34. US Government Printing Office: Washington DC.

Hagerup, L. M. (1973). Coronary heart disease risk factors in men and women. Acta medica Scandinavica Supplement 557, 46-51.

Hjermann, I., Helgeland, A., Holme, I., Lund-Larsen, P. G., and Leren, P. (1976). The intercorrelation of serum cholesterol, cigarette smoking and body weight. The Oslo study. Acta medica Scandinavica, 200, 479485.

Holme, I., Helgeland, A., Hjermann, I., Lund-Larsen, P. G., and Leren, P. (1976). Coronary risk factors and socioeconomic status. The Oslo study. Lancet, 11, 1396-1398.

Leren, P., Askevold, E. M., Foss, O. P., Frøili, A., Grymyr, D., Helgeland, A., Hjermann, I., Holme, I., Lund-Larsen, P. G., and Norum, K. R. (1976). The Oslo study. Cardiovascular disease in middle-aged and young Oslo men. Acta medica Scandinavica, Supplement 588, 1-38.

Natvig, H., Borchgrevink, C. F., Dedichen, J., Owren, P. A., Schiøtz, E. H., and Westlund, K. (1968). A controlled trial of the effect of linolenic acid on incidence of coronary heart disease. The Norwegian vegetable oil experiment of 1965-66. Scandinavian Journal of Clinical and Laboratory Investigation, 22, Supplement 105, 1-20.

Ostrander, L. D. (1976). Coronary risk factors in a community. Findings in Tecumseh, Michigan. Circulation, 53, 152-156.

Pincherle, G., and Robinson, D. (1974). Mean blood pressure and its relation to other factors determined at a routine executive health examination. Journal of Chronic Diseases, 27, 245-260.

Ralston, A., and Wilks, H. S. (1960). Mathematical methods for digital computers. John Wiley and Sons: New York.

Rose, G. A., and Blackburn, H. (1968). Cardiovascular survey methods. WHO Monograph Series No. 56, pp. 90-93. WHO: Geneva.

Stamler, J., Berkson, D. M., Dyer, A., Lepper, M. H., Lindeberg, H. A., Paul, O., McLean, H., Romberg, P., Schoenberger, J. A., Shekelle, R. B., and Stamler, R. (1975). Relationship of multiple variables to blood pressure-findings from four Chicago epidemiological studies. In Epidemiology and Control of Hypertension, pp. 307-352. Stratton: New York.

Westlund, K., and Nicolaysen, R. (1972). Ten year mortality and morbidity related to serum cholesterol. Scandinavian Journal of Clinical and Laboratory Investigation, 30, Supplement 127, 1-24.

Wilhelmsen, L., Wedel, H., and Tibblin, G. (1973). Multivariate analysis of risk factors for coronary heart disease. Circulation, 48, 950-958. 